\title{
Membrane Bistability in Olfactory Bulb Mitral Cells
}

\author{
Philip Heyward, Matthew Ennis, Asaf Keller, and Michael T. Shipley \\ Department of Anatomy and Neurobiology and the Program in Neuroscience, University of Maryland School of Medicine, \\ Baltimore, Maryland 21201
}

\begin{abstract}
Whole-cell patch-clamp recordings were used to investigate the electrophysiological properties of mitral cells in rat main olfactory bulb brain slice preparations. The majority of mitral cells are bistable. These cells spontaneously alternate between two membrane potentials, separated by $\sim 10 \mathrm{mV}$ : a relatively depolarized potential (upstate), which is perithreshold for spike generation, and a relatively hyperpolarized potential (downstate), in which spikes do not occur. Bistability occurs spontaneously in the absence of ionotropic excitatory or inhibitory synaptic inputs. Bistability is voltage dependent; transition from the downstate to the upstate is a regenerative event activated by brief depolarization. A brief hyperpolarization can switch the
\end{abstract}

The initial site of olfactory processing in vertebrate species is the main olfactory bulb (MOB). The MOB is a phylogenetically conserved cortical structure, with well defined architecture (Ramon y Cajal, 1894). The principal neurons of the MOB, the mitral cells, are located in a single lamina, the mitral cell layer (MCL); their dendrites span the MOB. The olfactory nerve (ON) synapses with mitral cell apical dendrites in the olfactory glomeruli, where interactions with juxtaglomerular interneurons occur. Mitral cell lateral dendrites interact with inhibitory granule cells, within the external plexiform layer (EPL). Although the morphology, projections, and synaptic interactions of mitral cells have been described (Shipley and Ennis, 1996; Shipley et al., 1996), only recently have in vitro mammalian MOB preparations allowed detailed study of mitral cell electrophysiology.

Recent investigations using rodent brain slices have elucidated neurotransmission between the $\mathrm{ON}$ and mitral cells (Ennis et al., 1996; Aroniadou-Anderjaska et al., 1997; Ciombor et al., 1999) and between mitral cell lateral dendrites and granule cells (Isaacson and Strowbridge, 1998; Schoppa et al., 1998; AroniadouAnderjaska et al., 1999a; Chen et al., 2000). Other studies have provided evidence of excitatory interactions among mitral cell lateral dendrites (Aroniadou-Anderjaska et al., 1999a,b; Isaacson, 1999; Friedman and Strowbridge, 2000) and intraglomerular excitatory interactions among mitral cell apical dendrites (Carlson et al., 2000).

Neurons express a wide variety of electroresponsive properties

Received Dec. 27, 2000; revised April 12, 2001; accepted April 25, 2001.

This work was supported in part by United States Public Health Service Grants NS36940, NS31078, DC00347, and DC03195. We are grateful for critical comments and discussion provided by Drs. B. E. Alger and D. Weinreich and for technical assistance with histological processing and analysis performed by Dr. C. Priest and Y. Tian.

Correspondence should be addressed to Dr. Michael T. Shipley, Department of Anatomy and Neurobiology, Program in Neuroscience, University of Maryland School of Medicine, 685 West Baltimore Street, Baltimore, MD 21201. E-mail: mshipley@umaryland.edu.

Copyright @ $\odot 2001$ Society for Neuroscience 0270-6474/01/215311-10\$15.00/0 membrane potential from the upstate to the downstate. In response to olfactory nerve (ON) stimulation, mitral cells in the upstate are more likely to fire an action potential than are those in the downstate. ON stimulation can switch the membrane potential from the downstate to the upstate, producing a prolonged and amplified depolarization in response to a brief synaptic input. We conclude that bistability is an intrinsic property of mitral cells that is a major determinant of their responses to $\mathrm{ON}$ input.

Key words: mitral cell; bistability; main olfactory bulb; plateau potential; upstate; downstate; response to olfactory nerve

(Llinas, 1988). Specific intrinsic membrane properties can endow individual neurons with multiple firing thresholds, levels of excitability, and modes of oscillatory behavior (Llinas, 1988). Thus, intrinsic properties are a major determinant of synaptic integration (see also Johnston et al., 1996). However, although recent studies have expanded our knowledge of MOB synaptic interactions, relatively little is known about the membrane properties of MOB neurons.

Mitral cell apical dendrites propagate unattenuated action potentials (Bischofberger and Jonas, 1997; Chen et al., 1997) and, under some conditions, may be a site of action potential initiation in response to ON input (Chen et al., 1997). Mitral cell membrane properties may influence the timing of spike output, in response to ON stimulation (Desmaisons et al., 1999), whereas granule cell membrane properties may regulate the timing of inhibitory synaptic output, generated in response to mitral cells (Schoppa and Westbrook, 1999). How mitral cell membrane properties may influence synaptic integration and their role in the formation of multiphasic responses to ON input (Ennis et al., 1996; Jiang et al., 1996; Aroniadou-Anderjaska et al., 1997; Ciombor et al., 1999) remain unclear. The present study therefore further investigated the membrane properties of mitral cells. The results show that mitral cells are bistable, maintaining two levels of membrane potential with different responsiveness to $\mathrm{ON}$ input. Active properties of the mitral cell membrane, operating at potentials subthreshold for spike generation, can amplify and extend in time the influence of both depolarizing and hyperpolarizing inputs. These mechanisms significantly influence mitral cell responses to $\mathrm{ON}$ synaptic input.

Parts of this paper have been published previously (Ennis et al., 1997; Heyward and Shipley, 1999, 2000a,b; Heyward et al., 1999).

\section{MATERIALS AND METHODS}

Sprague Dawley rats (30-45 d old and of either sex) were decapitated in accordance with Institutional Animal Care and Use Committee and National Institutes of Health guidelines. The MOB was dissected, and 
$400-\mu \mathrm{m}$-thick horizontal slices, cut parallel to the long axis of the MOB, were prepared under ice-cold recording medium (see below) using a Vibratome (Vibratome 1000; Technical Products International, St. Louis, MO). Slices cut from 800 to $2200 \mu \mathrm{m}$ from the ventral surface of the $\mathrm{MOB}$ were then maintained at $30 \pm 0.5^{\circ} \mathrm{C}$ in a perfusion bath mounted on a microscope stage. Slices were submerged in medium flowing at $2.5-3 \mathrm{ml} / \mathrm{min}$ and allowed to recover for at least $1 \mathrm{hr}$ before recording. Experiments continued, under these conditions, for up to $7 \mathrm{hr}$ in vitro.

Two methods of visualization were used: the "blind" technique (Blanton et al., 1989) and near-infrared differential interference contrast (NIR DIC) (Stuart et al., 1993). For the blind technique, oblique incident illumination from a submerged fiber optic light guide $1 \mathrm{~mm}$ in diameter was used to visualize the MCL through an $80 \times$ stereomicroscope. For NIR DIC, water-immersion optics (BX50WI microscope; 40× waterimmersion objective; Olympus Optical, Tokyo, Japan) and videomicroscopy were used to visualize individual cells. NIR transillumination was at $900 \mathrm{~nm}$ (filter transmission, $850-950 \mathrm{~nm}$ ) concentric with the objective and optimized for DIC. A 0.25 inch CCD camera (CCD 100; Dage, Stamford, CT) fitted with a 3-to-1 direct zooming coupler (Optem, Fairport, NY) was used. Contrast was enhanced in real time using an image processor (model 794; Hughes Aircraft Company), and the image was displayed on a monochrome monitor (Dage HR120).

Recordings were made from the MCL, using conventional whole-cell patch-clamp methods. Recording pipettes were pulled on a FlamingBrown P-97 puller from standard-wall filamented borosilicate glass 1.5 $\mathrm{mm}$ in diameter. The tip diameter was $2-3 \mu \mathrm{m}$; tip resistance was $5-8$ $\mathrm{M} \Omega$. Seal resistance was routinely $>1 \mathrm{G} \Omega$. Data were obtained using an Axopatch 200B amplifier (Axon Instruments, Foster City, CA), recorded, and digitized on videotape (Vetter) and computer disk (Axoscope/ Clampex; Axon Instruments). Holding currents were generated by the recording amplifier, under manual control. Membrane resistance was calculated from the amount of steady-state current required to hyperpolarize the resting potential of the cells by $5 \mathrm{mV}$, from -60 to $-65 \mathrm{mV}$. Distributions of membrane potential were constructed by all-points analysis of digitized records (pClamp; Axon Instruments), with voltage data points (excluding action potential peaks) in digitized records (sampled at $2 \mathrm{kHz}$ ) binned by amplitude. Curve fitting, latency, and duration measurements were performed using pClamp analysis software (Axon Instruments). Numerical data are expressed as the mean \pm SEM. Unless otherwise described, tests for statistical significance were performed using Student's $t$ test.

Olfactory nerve stimulation. The ON was stimulated (Grass S8800 stimulator; Astro-Med, West Warwick, RI) using a twisted stainless-steel wire electrode (70 $\mu \mathrm{m}$ in diameter), which was insulated except for the tip, with constant-current stimuli of $10-200 \mu \mathrm{A}$. The stimulus duration was $0.1 \mathrm{msec}$. The stimulation electrode was positioned to lie radial to the MCL recording site, within the ON layer.

Drugs and solutions. The standard bathing medium consisted of (in $\mathrm{mm}$ ): $\mathrm{NaCl} 120, \mathrm{KCl} 3, \mathrm{CaCl}_{2} 1.3, \mathrm{MgSO}_{4} 1.3$, glucose $10, \mathrm{NaHCO}_{3} 25$, and $\mathrm{BES} 5, \mathrm{O}_{2} / 5 \% \mathrm{CO}_{2}$ saturated, $\mathrm{pH} 7.27$, and $300 \mathrm{mOsm}$ (Heyward et al., 1995). The standard pipette-filling solution consisted of (in $\mathrm{mM}$ ): $\mathrm{K}$ gluconate 125, $\mathrm{MgCl}_{2}$ 2, HEPES 10, $\mathrm{Mg}_{2} \mathrm{ATP} 2, \mathrm{Na}_{3}$ GTP $0.2, \mathrm{NaCl} 1$, and BAPTA or EGTA 0.2, pH 7.2 and 290-300 mOsm. Experiments were also performed using a high- $\mathrm{Cl}^{-}$pipette-filling solution consisting of (in mM): $\mathrm{KCl} 55, \mathrm{~K}_{2} \mathrm{SO}_{4} 75, \mathrm{NaCl} 1, \mathrm{MgCl}_{2} 2$, HEPES 10, $\mathrm{Mg}_{2} \mathrm{ATP} 2$, $\mathrm{Na}_{3}$ GTP 0.2, and BAPTA 0.2, pH 7.2 and 290-300 mOsm.

Pharmacological agents were applied via the bathing medium. 2-OHsaclofen and 6-cyano-7-nitroquinoxaline-2-3-dione (CNQX) were supplied by Research Biochemicals (Natick, MA). Bicuculline (bic), D,L-2amino-5-phosphonopentanoic acid (AP-5), SR-95531 (gabazine), and recording medium and pipette solution components were from Sigma (St. Louis, MO). Bicuculline (free base) was dissolved according to the method of Curtis et al. (1971).

Histology. Biocytin (0.05-0.1\%; E-biotinoyl-L-lysine; Molecular Probes, Eugene OR) was routinely added to the pipette-filling solution to allow examination of recorded cells after recording. The presence of biocytin had no evident effect on mitral cell electrophysiology. After recording, slices were fixed by immersion in phosphate-buffered $4 \%$ paraformaldehyde at $0-4^{\circ} \mathrm{C}$ and kept at least overnight in the fixative at $4^{\circ} \mathrm{C}$. Fixation at low temperature prevents reversal of the beading of neuronal processes (Ochs et al., 1997), an early morphological sign of degenerative changes in neurons (Faddis et al., 1997). Whole slices were processed using a commercial avidin-biotin kit (Elite) with diaminobenzidine (DAB; $0.2 \mathrm{mg} / \mathrm{ml}$ ) as the chromogen. To allow mitral cells to be visualized without resectioning the slices, the DAB signal was intensified as follows. Each incubation was performed in the dark, and between each step, slices were washed in $300 \mathrm{~mm}$ sucrose. Slices were first incubated for $1 \mathrm{hr}$ at $56^{\circ} \mathrm{C}$ in freshly prepared $1.4 \% \mathrm{AgNO}_{3}$ solution. Slices were then incubated at room temperature in $5 \% \mathrm{Na}_{2} \mathrm{~S}_{2} \mathrm{O}_{3}$, followed by incubation for $20 \mathrm{~min}$ at room temperature in $0.2 \% \mathrm{HAuCl}_{4}$ and then finally for 30 min in $5 \% \mathrm{Na}_{2} \mathrm{~S}_{2} \mathrm{O}_{3}$. Processed slices were whole mounted, dehydrated, and cleared through an ethanol-xylene series.

\section{RESULTS}

\section{Spontaneous activity}

Mitral cells had one of two distinct forms of spontaneous activity, which we designate here "bistable" and "nonbistable" (Fig. 1). In recordings obtained with the blind method, $67 \%(42 / 62)$ of mitral cells were bistable, and $33 \%$ (20/62) were nonbistable. The blind method provided recordings from a random sample of cells in the MCL, irrespective of depth within the tissue. Using NIR DIC videomicroscopy $(n=120)$, the relative numbers of bistable and nonbistable cells were found to vary with depth in the slice (see below).

Bistable cells (Fig. $1 A$ ) spontaneously generated two discrete membrane potentials separated by $\sim 10 \mathrm{mV}$. (1) A relatively depolarized membrane potential $(-51 \pm 0.6 \mathrm{mV})$, perithreshold for action potential generation, was designated the "upstate." Small voltage oscillations (Desmaisons et al., 1999) and action potentials occurred in the upstate. (2) A relatively hyperpolarized membrane potential $(-61.5 \pm 0.7 \mathrm{mV})$ was designated the "downstate." Voltage oscillations and action potentials did not occur in the downstate. The difference between upstate and downstate potentials was $10.5 \pm 0.4 \mathrm{mV}$ (range, 6-18 mV). Bistable mitral cells spontaneously alternated between the downstate and the upstate. The depolarizing transition from the downstate to the upstate was initially slow, with increasing slope on approach to the upstate. This transition, designated the "depolarizing ramp," was accurately described by a single (negative) exponential fit ( $\tau, 62 \pm 1.2 \mathrm{msec} ; n=10$ cells, 500 events) (Fig. $1 A$ ). To assess goodness of fit, the $\mathrm{SD}$ of the fit was used as an estimate of average deviation between the data and the fit. Across all fits, the estimated average deviation between fit and data was $0.265 \pm 0.009 \mathrm{mV}$. Fit residuals (obtained by subtracting fit functions from data traces) gave a horizontal trace at $0 \mathrm{mV}$.

There was a clear point of inflection at which the exponentially depolarizing ramp gave way to maintenance of the upstate. A slow (1.37 $\pm 0.06 \mathrm{mV} / 100 \mathrm{msec} ; n=250$ events, 10 cells $)$, linear depolarization occurred during the upstate (Fig. $1 A$ ). In contrast to the depolarizing ramp from the downstate to the upstate, transition from the upstate to the downstate was abrupt, after the generation of a single action potential.

The distribution of membrane voltages spontaneously generated by a bistable mitral cell is shown in Figure $2 B$. The plot represents the proportion of time spent by the cell at each membrane voltage during spontaneous activity. The distribution has two peaks, corresponding to the downstate and upstate. The mean duration of the downstate and associated exponential depolarization to the upstate was $263.5 \pm 6 \mathrm{msec}$ (range, 23-1500 msec; $n=700$ events in 10 cells); the mean upstate duration was $130.6 \pm 3.5 \mathrm{msec}$ (range, $20-500 \mathrm{msec} ; n=500$ events in 10 cells). The input resistance of bistable mitral cells was $124 \pm 10 \mathrm{M} \Omega$.

The mean rate of spontaneous action potential generation for bistable mitral cells was $2.95 \pm 0.25 \mathrm{~Hz}$, in good agreement with previous extracellular recordings (Ciombor et al., 1999). Although the majority of action potentials in bistable mitral cells were generated from the upstate, $\sim 40 \%$ of spontaneous action 


\section{A. Bistable Mitral Cell.}

B. Non-bistable Mitral Cell.

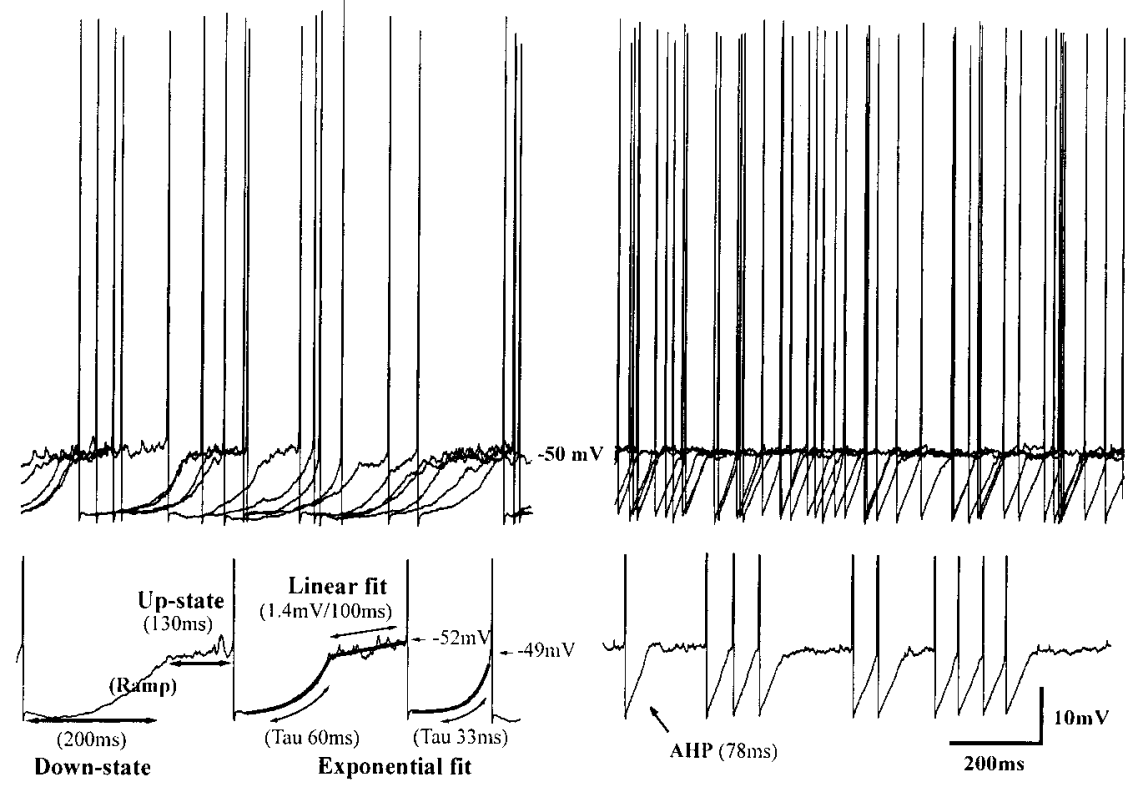

Figure 1. Mitral cell spontaneous activity. A, Bistable mitral cell. All traces are records of spontaneous activity in normal bathing media. Bistable mitral cells spontaneously alternated between two levels of membrane potential, the upstate and downstate. Top, Five superimposed sweeps of spontaneous bistable activity at the resting potential. Two membrane potentials are apparent, a depolarized potential (upstate) characterized by perithreshold oscillations and a relatively hyperpolarized subthreshold potential (downstate). Bottom, A single sweep illustrating the quantified components of bistable activity (see Results), the downstate, terminated by an exponential depolarization to the upstate (Ramp), and the upstate. In the upstate, voltage oscillations were superimposed on a linear depolarization. A spontaneous spike terminated the upstate and reset the membrane potential to the downstate. Not all spikes were preceded by the upstate; such spikes were preceded by a greater rate of exponential depolarization from the downstate and had a more negative activation threshold than did spikes initiated from the upstate. $B$, Nonbistable mitral cell. Nonbistable mitral cells maintained a single resting membrane potential and generated action potentials with a brief AHP. Top, Five superimposed sweeps of spontaneous nonbistable activity. Bottom, A single sweep recorded from the same cell. Numerical values are representative (see Results).

potentials were launched directly from the depolarizing ramp $(41 \pm 6.7 \% ; n=10$ cells). These action potentials ("ramp spikes") were initiated at more negative voltages $(-51.6 \pm 0.2 \mathrm{mV} ; n=$ 231 events in 3 cells) than were spikes initiated after generation of the upstate potential $(-49.5 \pm 0.6 \mathrm{mV} ; n=263$ events, 3 cells $)$ $(p<0.004)$ (Fig. 1A). After the generation of a ramp spike, membrane potential was reset to the downstate, without generation of the upstate. For ramp spikes, the mean rate of depolarization of the depolarizing ramp was significantly faster $(\tau=47 \pm$ 1 msec; $n=300$ events, 10 cells) than when the ramp led to the generation of an upstate $(\tau=76 \pm 2 \mathrm{msec} ; n=350$ events, 10 cells) $\left(p<10^{-8}\right)$ (Fig. $\left.1 A\right)$. This is consistent with the established sensitivity of spike threshold to both the rate of membrane depolarization and the steady-state voltage (Hodgkin and Huxley, 1952). Thus, when the rate of depolarization from the downstate was sufficiently high, an action potential was initiated from the ramp, and the membrane potential was reset to the downstate, without generation of the upstate. A positive correlation was found between the duration of the downstate and the duration of the following upstate (Pearson, $p<10^{-5}$ ). This interaction suggests that processes occurring during the downstate influence generation of the subsequent upstate. Bistable activity may therefore be influenced by interactions among specific membrane properties.

Nonbistable cells (Fig. $1 B$ ) maintained a single resting membrane potential $(52.5 \pm 0.8 \mathrm{mV})$, perithreshold for spike generation. As in the upstate of bistable mitral cells, small voltage oscillations occurred at this potential. A subthreshold potential equivalent to the downstate of bistable cells was not generated by these neurons. The duration of the spike afterhyperpolarization
(AHP) was $78 \pm 2.6 \mathrm{msec}(n=400$ events, 5 cells $)$, and repolarization of the spike AHP to the resting potential was approximately linear. The mean rate of spontaneous action potential generation in nonbistable cells was $3.8 \pm 0.8 \mathrm{~Hz}$, not significantly different from that of bistable cells. Figure 3 shows the distribution of membrane voltages spontaneously generated by a nonbistable mitral cell. The single peak of the distribution corresponds to the single resting potential maintained by nonbistable mitral cells. The input resistance of nonbistable cells, $138 \pm 14 \mathrm{M} \Omega$, was not significantly different from that of bistable mitral cells.

\section{The proportion of bistable and nonbistable mitral cells varied with depth in the slice}

The characteristics of bistable and nonbistable mitral cells were similar whether recorded with blind or NIR DIC methods. However, using NIR DIC, we observed a relationship between the depth of cells from the cut surface of the brain slice and their membrane properties. Depth within the slice was noted for 47 mitral cells identified by NIR DIC videomicroscopy, using the graduated fine focus control of the microscope. Mitral cell bodies and processes were visualized clearly within $50-70 \mu \mathrm{m}$ of the upper cut surface. Cell processes could not be visualized at depths $>70 \mu \mathrm{m}$, and cell bodies could not be distinguished at depths $>100-120 \mu \mathrm{m}$. By the use of established criteria for viability, cells presenting an apparently smooth surface without obvious swelling [indicative of impending lysis (Dodt, 1992)] or granularity (Edwards and Konnerth, 1992) were selected for recording. Such apparently viable cells were seen in greater numbers deeper in the slice. Of 28 cells recorded within the superficial $50 \mu \mathrm{m}$ of the slice, only 1 (3\%) was bistable, and 27 
A

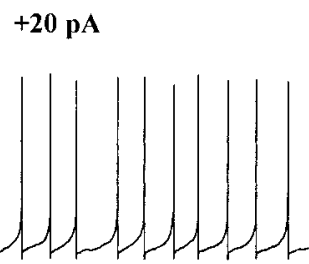

B
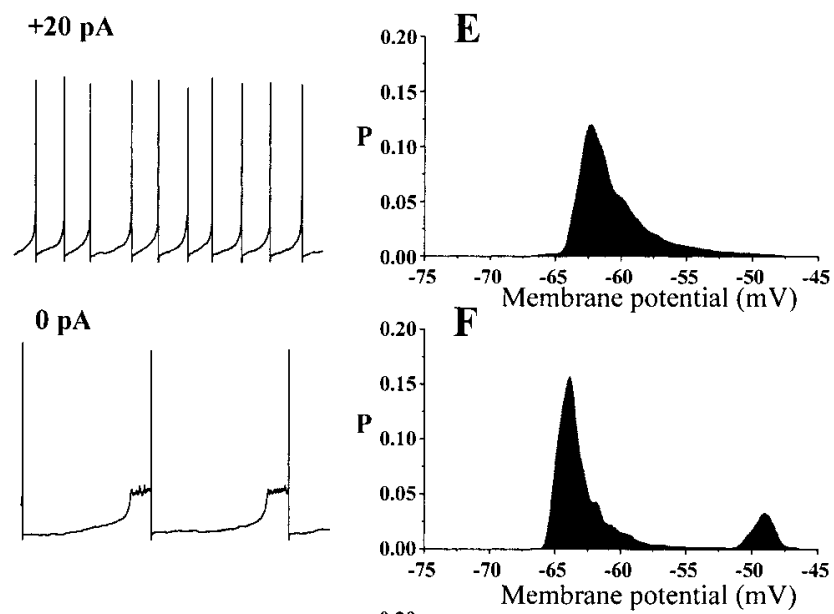

$\mathrm{C}$

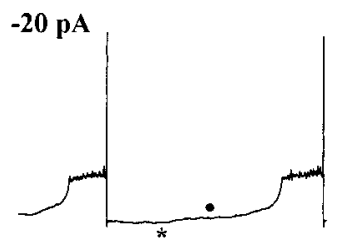

D $-50 \mathrm{pA}$

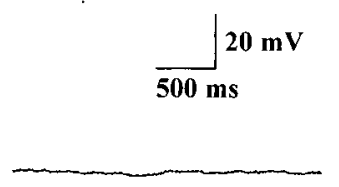

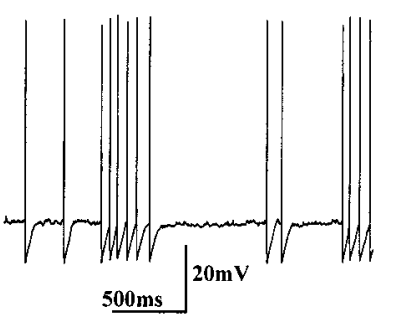

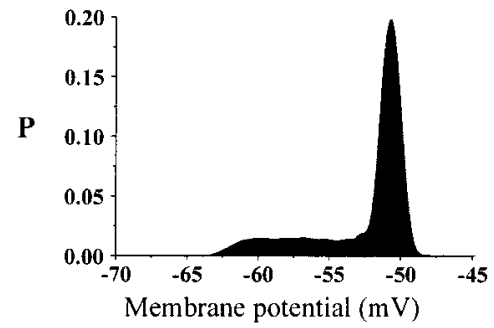

Figure 3. The membrane potential distribution (see Fig. 2 legend) of nonbistable cells has a single mode. The single peak of the plot reflects the single interspike membrane potential maintained by nonbistable mitral cells. Points to the left of the peak reflect the approximately linear recovery from the spike AHP to rest.

A zone of damaged tissue can extend $50-100 \mu \mathrm{m}$ below the surface of brain slice preparations (Dingledine et al., 1980; Scholfield, 1981; Alger et al., 1984) and may typically extend to $\sim 70 \mu \mathrm{m}$ (Teyler, 1980). Neurons with extensive dendrites, such as mitral cells, may be particularly vulnerable to damage during slicing (Schwartzkroin, 1981). The association between proximity to the cut surface and nonbistability suggests that nonbistability may be associated with the trauma of slicing. There was, however, no apparent association between the presence or absence of bistability and the morphological appearance of neurons visualized post hoc with biocytin. For both bistable and nonbistable cells, lateral dendrites were inevitably truncated in the slice and showed wide variation in their length and distribution within the EPL. In addition, both bistable and nonbistable cells were found that were unresponsive to $\mathrm{ON}$ stimulation and had lost their apical dendritic glomerular tuft during slice preparation. Dendritic beading, a common manifestation of neuronal injury (Faddis et al., 1997), was not present in either bistable or nonbistable cells cold-fixed immediately after recording. The presence or absence of mitral cell bistability did not, therefore, appear to correlate with truncation of dendrites or with overt morphological signs of pathophysiology. It is possible, however, that membrane properties change before or in the absence of morphological changes or in response to factors released into (or lost from) the tissue as a result of injury. Further results, described next, are consistent with this possibility.

The electrophysiology of some bistable mitral cells changed over time. Approximately $20 \%$ of all cells that were initially bistable showed a gradual decrease in the duration of the downstate and a commensurate increase in time spent in the upstate. Their spontaneous activity eventually became indistinguishable from that of nonbistable cells. Loss of bistability was not coupled to a decrease in spike amplitude. When it occurred, the loss of bistability had a variable time course of 5-30 min. The low incidence $(20 \%)$ and variable time course (5-30 $\mathrm{min}$ ) of the loss of bistability suggest that it is not simply attributable to a "washout" effect, associated with equilibration of cytosol with pipettefilling solution. Finally, it is noteworthy that mitral cells never progressed spontaneously from nonbistable to bistable activity; when there was a change of spontaneous activity, it was always a loss of bistability. Taken together these results suggest that nonbistability may result from the loss of membrane properties, particularly in cells close to the cut surface of the slice. Accordingly, subsequent recordings were made from mitral cells located deeper than $\sim 70 \mu \mathrm{m}$ below the surface of the slice, where the majority of mitral cells maintained bistability. In these cells, we investigated whether mitral cell bistability is generated by synapsurface using this method (Scholfield, 1981). 


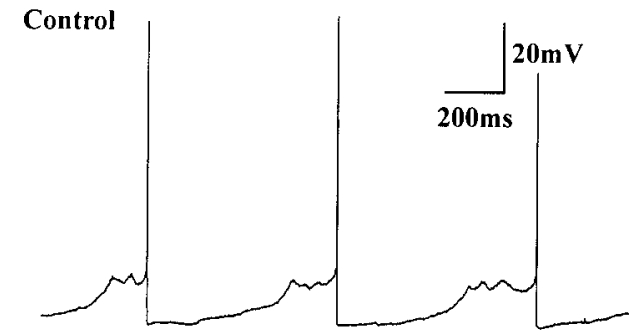

APV,CNQX,bic

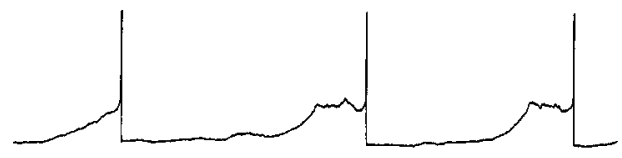

Figure 4. Mitral cell bistability was not dependent on excitatory or inhibitory synaptic inputs. Top, Control data recorded in normal bathing medium without synaptic blockers are shown. Bottom, Blockade of excitatory and inhibitory neurotransmission with CNQX (25 $\mu \mathrm{M})$, AP-5 $(A P V, 50 \mu \mathrm{M})$, and bic $(100 \mu \mathrm{M})$ did not abolish bistable activity in mitral cells (spikes truncated).

tic input to mitral cells or is based on their intrinsic membrane properties.

\section{Bistability is not dependent on synaptic input}

Bistable activity is generated by periodic synaptic input in some CNS neurons. A salient example of this is the spiny stellate cell (SSC) of the striatum (Wilson and Kawaguchi, 1996). In vivo, SSCs alternate between two membrane potentials, the more depolarized of which depends on excitatory synaptic input from the cortex (Wilson and Kawaguchi, 1996). In slice preparations, in which excitatory cortical inputs are severed, SSCs do not spontaneously exhibit the depolarized membrane potential. In the MOB slice preparation, ON excitatory synaptic inputs are present, and recent evidence indicates that local circuit activity in the olfactory glomerulus may produce long epochs of spontaneous depolarization in mitral cells in vitro (Carlson et al., 2000). Inhibitory inputs from granule cells are also preserved in the slice (Isaacson and Strowbridge, 1998; Schoppa et al., 1998; AroniadouAnderjaska et al., 1999a,b). Because major excitatory and inhibitory synapses are preserved in the MOB slice, it is possible that the bistable activity of mitral cells is a consequence of neuronal circuit activity.

To investigate this possibility, recordings were made in the presence of CNQX $(25 \mu \mathrm{M})$, AP-5 $(50 \mu \mathrm{M})$, and either bic $(10 \mu \mathrm{M}$; $n=10)$ or gabazine $(10 \mu \mathrm{M} ; n=10)$ to suppress ionotropic glutamatergic and GABAergic synapses. As shown in Figure 4, bistable activity was maintained despite pharmacological blockade of major excitatory and inhibitory synaptic inputs to mitral cells. Similar results were obtained using the broad-spectrum glutamate receptor antagonist kynurenic acid (1-5 mM; $n=5$; data not shown). Synaptic responses to ON stimulation were abolished under these conditions $(n=10)$. Furthermore, bistability was also maintained during extended recordings ( $>30 \mathrm{~min}$ ) made with high-chloride pipette-filling solution $\left(E_{\mathrm{Cl}},-18 \mathrm{mV}\right.$; $n=10)$. Thus, bistability does not depend on the presence of a hyperpolarizing chloride conductance, and mitral cell bistability, therefore, does not depend on $\mathrm{GABA}_{\mathrm{A}}, \mathrm{GABA}_{\mathrm{C}}$, or glycine receptor-mediated inhibition (Trombley et al., 1999). Furthermore, bistability was not sensitive to blockade of $\mathrm{GABA}_{\mathrm{B}}$ receptors using 2-OH-saclofen $(100-200 \mu \mathrm{M} ; n=3)$. Insensitivity to high intracellular chloride also suggests that bistability does not depend on G-protein-modulated ionic conductances, known to be depressed by elevated intracellular chloride (Lenz et al., 1997).

To investigate the influence of spontaneous synaptic activity, we analyzed mitral cell activity before and after inclusion of AP-5, CNQX, and gabazine in the recording medium (four cells; 2 min of recording from each cell, under each condition). There was no significant change in downstate duration, the time constant of the depolarizing ramp, or upstate slope (values in blockers were 105,102 , and $102 \%$ of control, respectively) or in spontaneous firing rate or the proportion of ramp spikes. Upstate duration, however, was increased to $134 \%$ of control in the presence of the blockers $(p=0.01)$. This suggests that the upstate potential, perithreshold for spike generation, is regulated by spontaneous synaptic inputs. Spontaneous synaptic activity may terminate the upstate by initiating an action potential.

\section{Bistability is generated by intrinsic membrane properties}

The preceding experiments indicate that mitral cells generate bistability in the absence of excitatory and inhibitory synaptic inputs. This suggests that mitral cell bistability is based on intrinsic membrane properties and may therefore involve voltagedependent events. We therefore investigated the voltage dependence of mitral cell bistability.

Voltage dependence of mitral cell bistability is shown in Figure 2. The membrane voltage distributions represent the proportion of time spent by a mitral cell at each membrane voltage (excluding action potentials), at rest and during the injection of hyperpolarizing or depolarizing current. At rest $(0 \mathrm{pA})$, the distribution is bimodal, the two peaks reflecting the upstate and the downstate (Fig. 2B,F). Voltage points corresponding to the exponential depolarization from the downstate to the upstate skew the peak corresponding to the downstate. With no current injected, hyperpolarized potentials, corresponding to the downstate, were predominant (Fig. 2B,F). With positive current injection, sufficient to depolarize membrane voltage by $2-3 \mathrm{mV}$ (Fig. $2 A, E$ ), spike generation became continuous, and neither the downstate nor the upstate was maintained. With negative current injection, sufficient to hyperpolarize membrane voltage by $1-2 \mathrm{mV}$ (Fig. $2 C, G$ ), the cell alternates between the downstate and the upstate less frequently, and an additional peak in the membrane potential distribution is present. This additional peak represents the holding potential attributable to the injection of negative current. With further hyperpolarization, all spontaneous activity is abolished (Fig. 2D), and the voltage distribution has a single peak corresponding to the holding potential (Fig. $2 H$ ).

These results indicate that bistable activity in mitral cells is voltage dependent, consistent with the generation of bistability by intrinsic, voltage-dependent mechanisms. In other neurons exhibiting intrinsic bistability, or plateau behavior, a brief depolarization can switch the membrane potential from the downstate to the upstate (Russell and Hartline, 1982; Marder et al., 1996). We tested for this property in mitral cells. In the presence of AP-5, CNQX, and bic, a transient, small (50-150 msec; 2-5 mV) depolarization could initiate transition from the downstate to the upstate (Fig. 5A,B). There was a threshold voltage $(2-5 \mathrm{mV}$ depolarized from the downstate) for initiating transition to the upstate. After this voltage was reached, the membrane depolarized exponentially to the upstate. Transition from the downstate to the upstate is therefore a voltage-dependent event and may involve active processes in the mitral cell membrane.

In other bistable neurons, a brief hyperpolarizing input can 
A

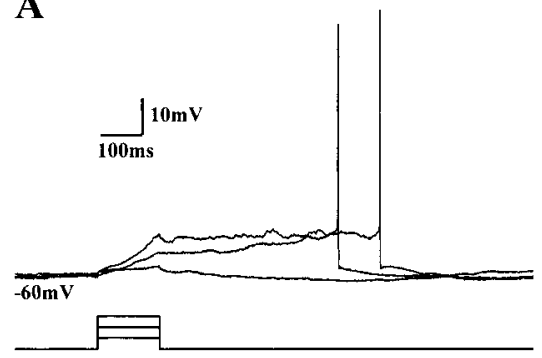

B

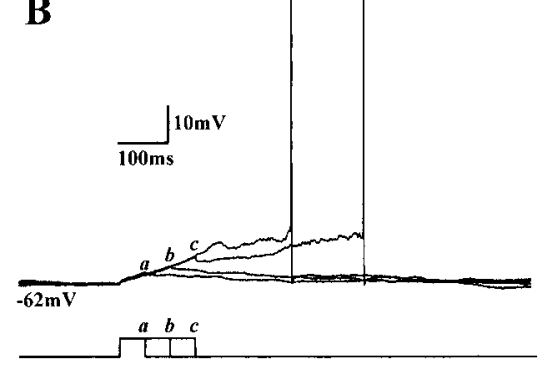

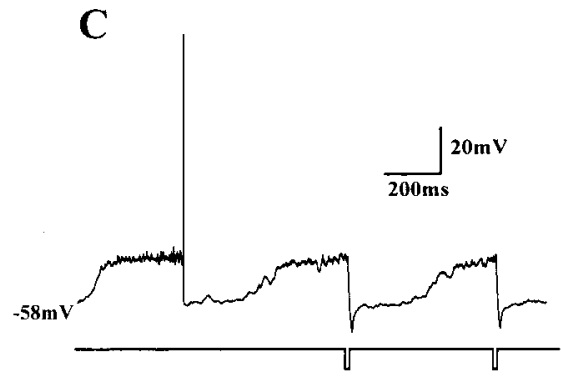

Figure 5. Voltage-dependent membrane properties are involved in the generation and maintenance of the upstate. $A$, Upstate generation in response to depolarizing pulses of increasing amplitude. Responses to three $180 \mathrm{msec}$ positive current pulses of increasing amplitude are shown. Pulses of sufficient amplitude are followed by the generation of the upstate. The upstate outlasts the duration of the depolarizing pulse. Transition to the upstate involves voltage-dependent membrane properties, activated by depolarization. $B$, Upstate generation in response to depolarizing pulses of increasing duration. Brief ( $a=50 \mathrm{msec} ; b=100 \mathrm{msec}$ ) depolarizing current pulses were followed by a return of the membrane potential to baseline. When pulse duration was sufficient $(c=150 \mathrm{msec})$, the threshold for initiating transition to the upstate was achieved, and the membrane actively depolarized to the upstate. Two traces are shown in response to the $150 \mathrm{msec}$ pulse. $C$, Brief hyperpolarization terminates the upstate. A spontaneous action potential terminates the upstate (at left). After spontaneous regeneration of the upstate, brief hyperpolarizing pulses (15 msec; below trace) delivered through the recording pipette terminate the upstate. $A$ and $B$ are from the same cell, in which hyperpolarizing holding current was used to prevent spontaneous depolarization to the upstate. All traces were recorded in the presence of CNQX, AP-5, and bic. The membrane potential existing at trace onset ( $\pm 0.5 \mathrm{mV})$ is shown in each panel (left).

shift the cell from the upstate to the downstate (Russell and Hartline, 1982; Kiehn, 1991; Marder et al., 1996; but also Williams et al., 1997). We tested for this property in mitral cells. As shown in Figure $5 C$, a mitral cell in the upstate could be reset to the downstate by a brief hyperpolarization (10-20 msec; $10-15$ $\mathrm{mV}$ ). Transition from the upstate to the downstate was abrupt, similar to that after a spontaneous action potential. The upstate potential can therefore be terminated by a brief hyperpolarizing event. This suggests that the upstate is maintained by voltagedependent mechanisms, deactivated by hyperpolarization. Furthermore, these results show that existence of the downstate does not depend on events, including synaptic output, generated during an action potential.

\section{Bistability influences mitral cell responses to ON synaptic input}

In general, the response of a neuron to synaptic input is influenced by its membrane potential (Williams et al., 1997). Thus, bistable mitral cells could be differentially responsive to $\mathrm{ON}$ synaptic input in the upstate and downstate. The upstate need not necessarily represent a state of increased neuronal excitability, however. If voltage inactivation of transient inward currents occurs during maintenance of the upstate plateau (Kay et al., 1998), the mitral cell could actually become less responsive to $\mathrm{ON}$ inputs. We therefore compared responses of mitral cells to synaptic input from the $\mathrm{ON}$, in the downstate, the upstate, and during depolarizing transition between states.

Mitral cells were more responsive to ON input in the upstate than in the downstate. When the ON was stimulated at sufficient intensity, a short-latency action potential was evoked in the upstate (Fig. 6). ON stimulation at the same intensity did not, however, evoke short-latency action potentials in the downstate (see below). Short-latency action potentials could be evoked from the downstate, however, if stimulus intensity was increased (Fig. 6). Although threshold intensities for short-latency spikes were not quantified systematically for the downstate, it was clear that stimulus intensities sufficient to produce short-latency spikes from the upstate did not evoke short-latency spikes in the downstate (see below). The upstate therefore represents a state of increased responsiveness to $\mathrm{ON}$ input.

As described previously both in vivo and in vitro by the use of
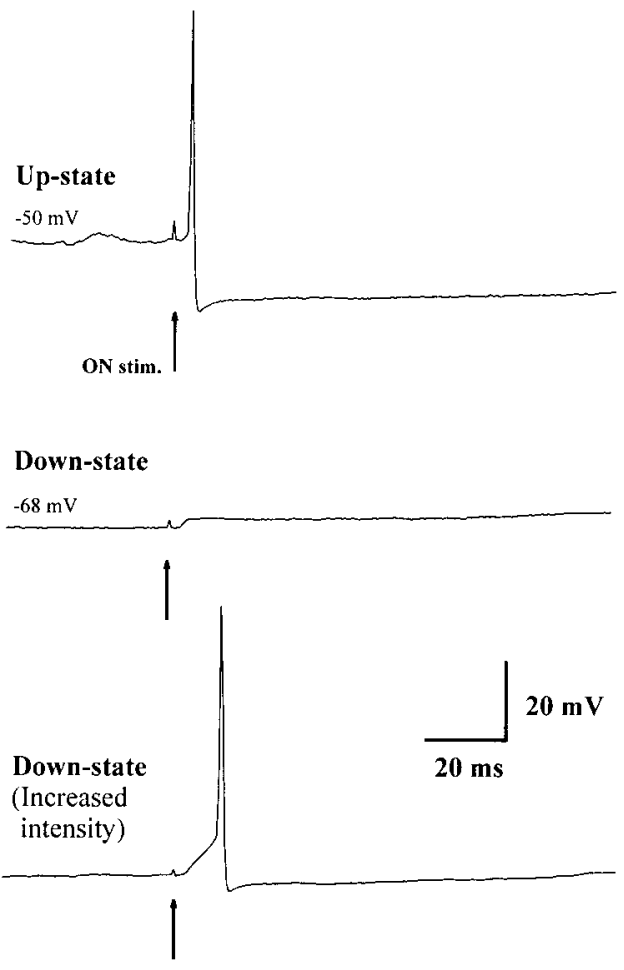

Figure 6. The upstate is more responsive to $\mathrm{ON}$ input than is the downstate. Top trace, ON stimulation $(80 \mu \mathrm{A})$ of a mitral cell in the upstate elicits a short-latency action potential (normal bathing medium). Stimulation intensity $(80 \mu \mathrm{A})$ was just sufficient to evoke an action potential in all trials in which the mitral cell was stimulated in the upstate. Center trace, ON stimulation at the same intensity in the downstate does not elicit a short-latency spike. Bottom trace, Spikes can be elicited from the downstate if stimulation intensity is increased $(150 \mu \mathrm{A})$. stim., Stimulation.

extracellular recording (Ennis et al., 1996; Jiang et al., 1996; Aroniadou-Anderjaska et al., 1997; Ciombor et al., 1999), lowfrequency $(0.5-0.2 \mathrm{~Hz}) \mathrm{ON}$ stimulation resulted in spikes that were bimodally distributed at short (less than $\sim 20 \mathrm{msec}$ ) and long (more than $\sim 80 \mathrm{msec}$ ) latencies. The two groups of action potentials were separated by an interval in which discharges did not 


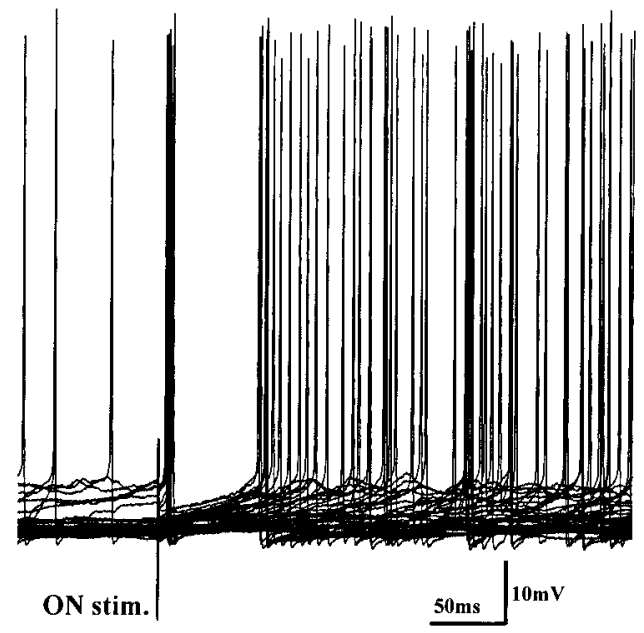

Figure 7. Mitral cell responses to ON stimulation consist of initial short-latency spikes, followed by an interval without spikes and then additional, longer latency spikes. The record shows superimposed sweeps generated over 50 consecutive ON stimuli delivered at $0.2 \mathrm{~Hz}$. Stimulation intensity was just sufficient to evoke a short-latency action potential in all trials in which the ON was stimulated when the mitral cell was in the upstate.

occur (Fig. 7). This response profile to ON stimulation was found in bistable cells but not in nonbistable cells. Nonbistable mitral cells responded with a single spike, or a burst of spikes (data not shown), initiated at short latency. In the present experiments, we investigated the relationship between bistable mitral cell membrane voltage and spike latency in whole-cell recording. Action potentials at long latency after afferent stimulation could be synaptically evoked or spontaneous events, unrelated to the stimulus. We therefore examined the relationship between membrane voltage and the latency to subsequent action potential generation, with and without ON stimulation at comparable membrane potentials (Figs. 8, 9). For this analysis, membrane voltages were divided into three ranges: the downstate, the depolarizing ramp, and the upstate. The depolarizing ramp from the downstate to the upstate was fitted by a single exponential (see above). Depolarizing ramp voltages were defined as all voltages less than two time constants of this exponential before the initiation of the upstate, and downstate voltages were defined as those greater than two time constants before generation of the upstate. Stimulus intensity was adjusted to be just sufficient to produce shortlatency action potentials in the upstate.

The relationship between mitral cell membrane voltage and spike latency is shown in Figures 8 and 9. The figures show the responses of a single mitral cell; equivalent data were obtained from analysis of the responses of an additional five cells. ON stimulation in the upstate evoked action potentials at short latency (control spike latency, $55 \pm 5 \mathrm{msec}$; ON-stimulated spike latency, $6.5 \pm 3 \mathrm{msec} ; p<3 \times 10^{-6}$ ) (Fig. $9 A, D$ ). ON stimulation at ramp voltages evoked spikes at either short latency or long latency (Fig. 9B,E) (control, $189 \pm 14 \mathrm{msec}$; ON stimulated, $98 \pm$ $\left.13 \mathrm{msec} ; p<7 \times 10^{-5}\right)$. The latency of the evoked spikes increased at voltages approaching the downstate. Short-latency spikes were not generated from ramp voltages in the absence of ON stimulation. ON stimulation at downstate voltages was followed only by long-latency action potentials (Fig. 9C,F). The latency of these long-latency action potentials is reduced from control values obtained for the same voltages without ON stim-
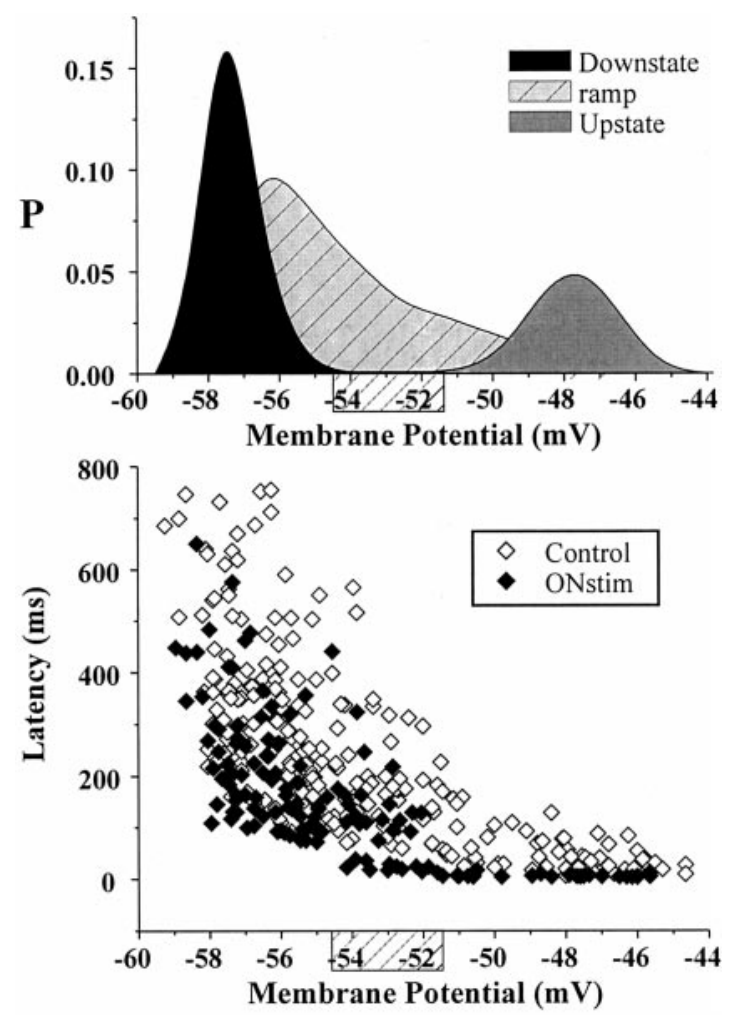

Figure 8. Spike latency in response to $\mathrm{ON}$ input depends on the prevailing mitral cell membrane potential. Top, The distribution of membrane potentials (see Fig. 2 legend) generated by a mitral cell during spontaneous activity was divided into three phases: downstate, depolarizing ramp, and upstate voltages. Voltages within two time constants of the termination of the exponential depolarizing ramp (see Results) are plotted separately, giving a region of no overlap (ramp voltages) between the upstate and downstate (hatched area on $x$-axis). This plot is derived from the voltage points used to construct the bottom plot, with which the $x$-axis corresponds. Stimulation intensity was just sufficient to evoke an action potential in all trials in which the mitral cell was stimulated in the upstate. Bottom, Latency to the first spike generated after ON stimulation (ONstim) at fixed intensity is plotted against the mitral cell membrane potential at the time of stimulation. Control data were derived from equivalent trials in which stimulus intensity was reduced to $0 \mathrm{pA}$. Data are derived from 300 stimulus trials (at $0.2 \mathrm{~Hz}$; solid symbols) and 300 control trials (open symbols) in one cell. ON stimulation decreases spike latency at all membrane voltages. In ON stimulus trials, the distribution of latencies is discontinuous, with a division of the response into short- and long-latency spikes. These data are shown in expanded form below (Fig. 9).

ulation (control, $344 \pm 14 \mathrm{msec}$; ON stimulated, $238 \pm 16 \mathrm{msec}$; $\left.p<7 \times 10^{-5}\right)$. Therefore, a significant proportion of long-latency action potentials can be considered as driven by the stimulus.

These results demonstrate that the response latency of a mitral cell to ON stimulation depends on the membrane potential of the cell and, furthermore, that synaptic input from the $\mathrm{ON}$ can initiate depolarization from the downstate to the upstate (Fig. $9 F$ ). This result agrees with the responses of mitral cells to brief depolarizing current injections to the soma (above), suggesting that synaptic depolarization of the apical dendrite interacts with voltage-dependent properties of the mitral cell membrane to initiate an active depolarization from the downstate to the upstate and ultimately to spike threshold.

\section{DISCUSSION}

We report that mitral cells are bistable. They maintain two discrete levels of membrane potential, separated by $\sim 10 \mathrm{mV}$, a 


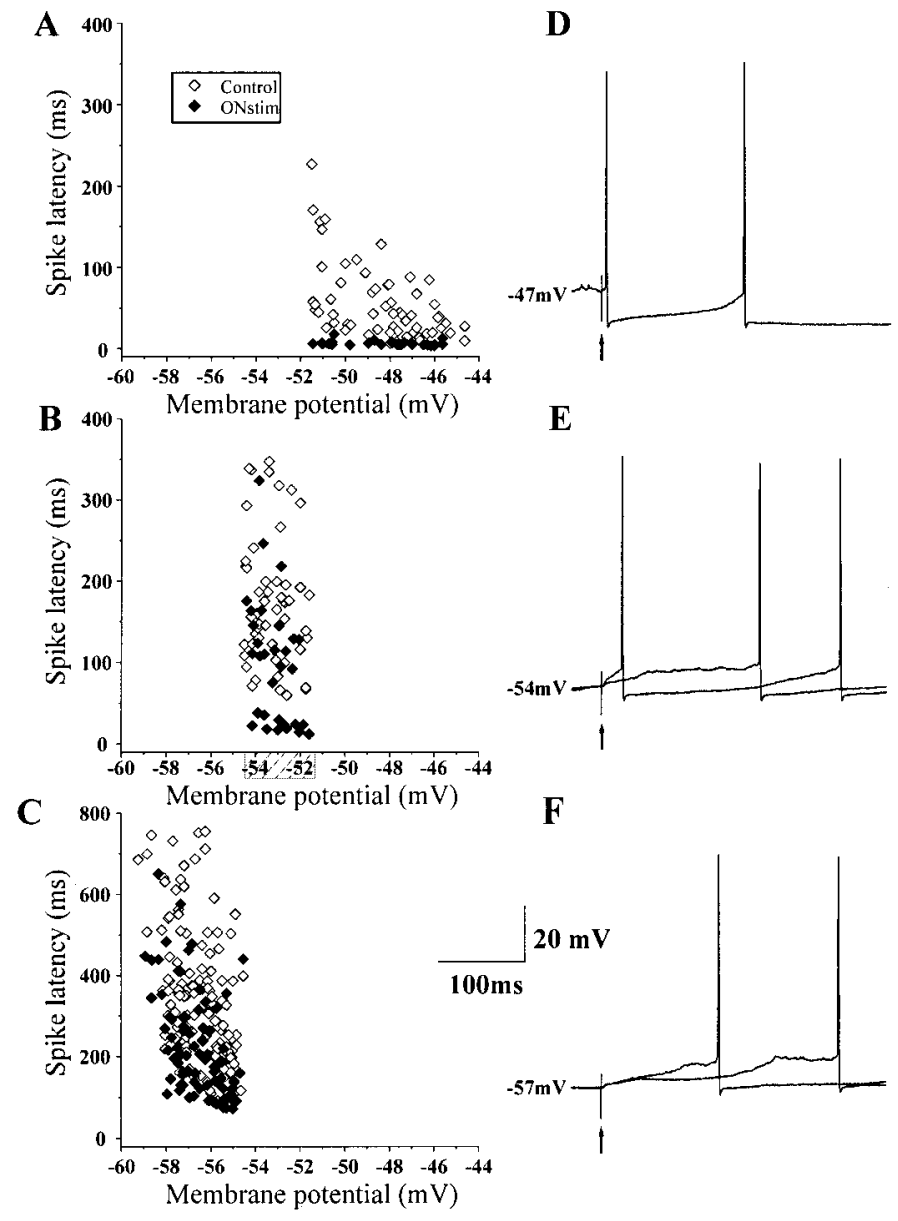

Figure 9. Mitral cell bistability influences responses to $\mathrm{ON}$ input, determining response latency. The data of Figure 8 are shown in expanded form, divided into upstate $(A)$, depolarizing ramp $(B)$, and downstate $(C)$ voltages. Representative traces corresponding to each range of voltages are to the right $(D-F) . A, D, \mathrm{ON}$ stimulation when the mitral cell is in the upstate elicits a short-latency spike. The latency of spikes elicited by ON stimulation in the upstate is clearly reduced in comparison with control. Spike latency is relatively invariant. $B, E$, ON stimulation at depolarizing ramp voltages elicits spikes at long or short latency. Short-latency spikes do not occur spontaneously at ramp voltages. $C, F$, ON stimulation at downstate voltages elicits long-latency spikes, preceded by generation of the upstate. Note the changed latency scale in $C$. These results suggest that active properties of the mitral cell membrane contribute to the response to ON stimulation ( $D$, single trace; $E, F$, two superimposed traces).

downstate subthreshold for spike generation and an upstate perithreshold for action potentials. Bistability determines mitral cell responses to ON stimulation and may have an important influence on MOB network activity.

\section{Is bistability an intrinsic property of mitral cells?}

Several findings indicate that bistability is an intrinsic property of mitral cells. First, bistability does not require ionotropic glutamatergic synaptic inputs. Bistability was present in mitral cells from which the apical dendritic tuft, the site of excitatory input from the ON, was cut. Moreover, bistability persisted when glutamatergic inputs were blocked pharmacologically. Bistability, therefore, results neither from excitatory input to mitral cells from the ON nor mitral cell autoexcitation or glutamate "spillover" (Aroniadou-Anderjaska et al., 1999a,b; Isaacson, 1999; Friedman and Strowbridge, 2000). Second, bistability does not require GABAergic inhibitory inputs. Bistability was observed in mitral cells despite truncation of lateral dendrites, the predominant locus of GABAergic inhibitory inputs (Shipley and Ennis, 1996; Shipley et al., 1996). Moreover, bistability persisted in the presence of $\mathrm{GABA}_{\mathrm{A}}$ receptor blockers and was maintained during changes in intracellular chloride concentration expected to reverse IPSPs. Thus, bistability requires neither GABAergic nor glycinergic (Trombley et al., 1999) neurotransmission.

Although modulatory synaptic inputs could play a role in the expression of bistability (Kiehn, 1991; Chuang et al., 2000; Mercer et al., 2000), additional evidence suggests that mitral cells are intrinsically bistable. Bistability is voltage dependent, and furthermore, brief inputs induce transition between the two states in the presence or absence of synaptic input. After being sufficiently depolarized from the downstate, mitral cells depolarize exponentially to the upstate. This is a voltage-dependent, active process. Conversely, a brief hyperpolarizing current pulse can switch the membrane from the upstate to the downstate. These findings indicate that intrinsic voltage-dependent mechanisms are involved in initiating both the upstate and the downstate. However, our results also suggest that these mechanisms can be altered after the trauma of slice preparation, with a consequent loss of bistability in mitral cells within $\sim 70 \mu \mathrm{m}$ of the cut surface of the slice.

The mitral cell upstate has the characteristics of a depolarized plateau potential (Llinas and Sugimori, 1980a,b; Jahnsen and Llinas, 1984a,b), a sustained depolarization initiated by a transient depolarizing input. Intrinsic plateau potentials occur in various mammalian central neurons (Yuen et al., 1995; Callaway and Ross, 1997; Mitmann et al., 1997; Bennet et al., 1998; Sandler et al., 1998; Beurrier et al., 1999; Schwindt and Crill, 1999; Chuang et al., 2000). In such neurons, the voltage of the plateau is determined by sustained voltage-dependent inward and outward currents (Yuen et al., 1995; Booth et al., 1997). Mitral cell bistability is consistent with the presence of a persistent $\mathrm{Na}^{+}$ current (for review, see Crill, 1996). Membrane potential oscillations such as those that occur in the upstate have been described in rat mitral cells in vitro (Desmaisons et al., 1999) and attributed to such a current. Our preliminary voltage-clamp data (Heyward and Shipley, 1999, 2000a,b) confirm the presence of a noninactivating TTX-sensitive current, activated in mitral cells at subthreshold potentials. The gradual depolarization during the upstate suggests that inward current underlying the upstate is opposed by slowly inactivating outward current.

The upstate can be switched to the downstate by a brief hyperpolarization. This suggests that the upstate can be terminated by deactivation of inward current. Unlike bistable neurons in mammalian spinal cord (Kiehn, 1991) or cerebellum (Llinas and Sugimori, 1980a,b; Yuen et al., 1995; Callaway and Ross, 1997) or invertebrate neurons (Russell and Hartline, 1982; Marder et al., 1996), the mitral cell upstate can be terminated by the generation of a single spike. Mitral cell apical dendrites support the generation of unattenuated action potentials (Bischofberger and Jonas, 1997; Chen et al., 1997). Outward currents activated during the generation of a single spike are evidently sufficient to deactivate inward current(s) maintaining the upstate. The downstate, then, is the potential maintained after deactivation of inward current underlying the upstate. The downstate represents an equilibrium that can be perturbed, by a brief depolarization, to produce active depolarization to the upstate.

Transition from the downstate to the upstate proceeds exponentially. Interaction between a regenerative, sustained inward 
current and an inactivating outward current could produce such a depolarization, the rate of which may be limited by the inactivation kinetics of the outward current. Preliminary voltage-clamp studies (Heyward and Shipley, 1999, 2000a) show an inactivating outward current in mitral cells, activated by depolarization from downstate voltages, which is reduced in nonbistable mitral cells.

Exponential depolarization from the downstate leads either to generation of the upstate or to initiation of a spike directly from the ramp (ramp spikes). Ramp spikes were preceded by a greater rate of depolarization from the downstate and had a more negative activation threshold than did spikes initiated from the upstate. This is consistent with the established relationship between the rate of depolarization and spike threshold (Hodgkin and Huxley, 1952). When an upstate is generated, exponential depolarization from the downstate is abruptly terminated before spike initiation and replaced by a slow linear depolarization, with superimposed voltage oscillations. Outward current activation at upstate voltages is apparently sufficient to halt exponential depolarization to spike threshold. When the slow upstate depolarization brings the membrane to spike threshold, a spike is initiated, and the upstate is terminated.

In summary, the results suggest that mitral cells are inherently bistable. We propose that the upstate represents a depolarized plateau potential that may be deactivated by hyperpolarization, such as that occurring after an action potential. The downstate is an equilibrium maintained until sufficient depolarization occurs to initiate active depolarization to the upstate. After being initiated, transition from the downstate to the upstate proceeds exponentially, the rate of depolarization influencing spike threshold.

\section{Functional implications}

The upstate and downstate represent two levels of responsiveness to $\mathrm{ON}$ input. The upstate is perithreshold for spike generation; the downstate is subthreshold. A broader range of depolarizing input amplitudes may thus be processed in the downstate, without generating a short-latency spike, than in the upstate, effectively extending the dynamic range of mitral cells. When excitatory input in the downstate is sufficient, transition to the upstate occurs. Transition to the upstate is an active process that effectively amplifies the voltage change produced by transient depolarizing currents. The upstate may therefore amplify the somatic effect of ON synaptic input to the apical dendrite.

Action potential generation by mitral cells projecting to the same glomerulus and therefore with the same response specificity (Mombaerts et al., 1996) may be periodically synchronized via long-lasting depolarizations involving excitatory interactions among their apical dendrites (Carlson et al., 2000). Because mitral cells are reset to the downstate after spike generation, mitral cells coupled to the same glomerulus may be coordinately reset to the downstate. Thus, subthreshold processing of $\mathrm{ON}$ input could occur synchronously in multiple mitral cells with the same response specificity. The specificity of mitral cell output may also be enhanced by bistability, via lateral inhibitory interactions between mitral and granule cells. The downstate comprises a prolonged decrease in excitability after a transient hyperpolarization. Activation of mitral cells associated with a specific glomerulus may, via lateral inhibition, prolong a state of low excitability, the downstate, in mitral cells associated with glomeruli of different response specificity. Such interactions among mitral cells, mediated via granule cells, could sharpen the specificity of MOB output (Yokoi et al., 1995). In this way, the downstate would act as a filter against relatively weak or nonspecific inputs, the effectiveness of which may be varied by local circuit activity. In behaving mammals, olfactory input is periodic (Halpern, 1983), in synchrony with respiration, or sniffing [typically at $5-11 \mathrm{~Hz}$ in rat (Waranch and Terman, 1975)]. Mitral cell bistability, therefore, could also function to integrate across sniff cycles by extending the duration of subthreshold postsynaptic responses to input from the ON.

\section{REFERENCES}

Alger BE, Dhanjal SS, Dingledine R, Garthwaite J, Henderson G, King GL, Lipton P, North A, Schwartzcroin PA, Sears TA, Segal M, Whittingham TS, Williams J (1984) Brain slice methods. In: Brain slices (Dingledine R, ed), pp 381-437. New York: Plenum.

Aroniadou-Anderjaska V, Ennis M, Shipley MT (1997) Glomerular synaptic responses to olfactory nerve input in rat olfactory bulb slices. Neuroscience 79:425-434.

Aroniadou-Anderjaska V, Ennis M, Shipley MT (1999a) Current-source density analysis in the rat olfactory bulb: laminar distribution of kainate/AMPA- and NMDA-receptor-mediated currents. J Neurophysiol 81:15-28.

Aroniadou-Anderjaska V, Ennis M, Shipley MT (1999b) Dendrodendritic recurrent excitation in mitral cells of the rat olfactory bulb. J Neurophysiol 82:489-494.

Bennet DJ, Hultborn H, Fedirchuk B, Gorassini M (1998) Short-term plasticity in hindlimb motoneurons of decerebrate cats. J Neurophysiol 80:2038-2045.

Beurrier C, Congar P, Bioulac B, Hammond C (1999) Subthalamic neurons switch from single spike activity to burst firing mode. J Neurosci 19:599-609.

Bischofberger J, Jonas PJ (1997) Action potential propagation into the presynaptic dendrites of rat mitral cells. J Physiol (Lond) 504:359-365.

Blanton MG, Lo Turco JJ, Kriegstein AR (1989) Whole cell recording from neurons in slices of reptilian and mammalian cerebral cortex. J Neurosci Methods 30:203-210.

Booth V, Rinzel J, Kiehn O (1997) Compartmental model of vertebrate motoneurons for $\mathrm{Ca}^{2+}$-dependent spiking and plateau potentials under pharmacological treatment. J Neurophysiol 78:3371-3385.

Callaway JC, Ross WN (1997) Spatial distribution of synaptically activated sodium concentration changes in cerebellar Purkinje neurons. J Neurophysiol 77:145-152.

Carlson GC, Shipley MT, Keller A (2000) Long-lasting depolarizations in mitral cells of the rat olfactory bulb. J Neurosci 20:2011-2021.

Chen WR, Midtgaard J, Shepherd GM (1997) Forward and backward propagation of dendritic impulses and their synaptic control in mitral cells. Science 278:463-476

Chen WR, Xiong W, Shepherd GM (2000) Analysis of relations between NMDA receptors and GABA release at olfactory bulb reciprocal synapses. Neuron 25:625-633.

Chuang S-C, Bianchi R, Wong RKS (2000) Group I mGluR activation turns on a voltage-gated inward current in hippocampal pyramidal cells. J Neurophysiol 83:2844-2853.

Ciombor KJ, Ennis M, Shipley MT (1999) Norepinephrine increases rat mitral cell excitatory responses to weak olfactory nerve input via alpha-1 receptors in vitro. Neuroscience 90:595-606.

Crill WE (1996) Persistent sodium current in mammalian central neurons. Annu Rev Physiol 58:349-362.

Curtis DR, Duggan AW, Felix D, Johnston GAR (1971) Bicuculline, an antagonist of GABA and synaptic inhibition in the spinal cord of the cat. Brain Res 32:69-76.

Desmaisons D, Vincent JD, Lledo PM (1999) Control of action potential timing by intrinsic subthreshold oscillations in olfactory bulb output neurons. J Neurosci 19:10727-10737.

Dingledine R, Dodd J, Kelly JS (1980) The brain slice preparation as a useful neurophysiological preparation for intracellular recording. J Neurosci Methods 2:323-362.

Dodt H-U (1992) Infrared videomicroscopy of living brain slices. In: Practical electrophysiological methods (Katenman H, Grantyn R, eds), pp 6-10. New York: Wiley.

Edwards FA, Konnerth A (1992) Patch-clamping cells in sliced tissues. Methods Enzymol 207:208-222.

Ennis M, Zimmer LA, Shipley MT (1996) Olfactory nerve stimulation activates rat mitral cells via NMDA and non-NMDA receptors in vitro. NeuroReport 7:989-992.

Ennis M, Carlson GC, Keller A, Shipley MT, Heyward PM (1997) Multistable membrane properties of main olfactory bulb (MOB) mitral cells. Soc Neurosci Abstr 23:500.1.

Faddis BT, Hasbani MJ, Goldberg MP (1997) Calpain activation contributes to dendritic remodeling after brief excitotoxic injury in vitro. J Neurosci 17:951-959. 
Friedman D, Strowbridge BW (2000) Functional role of NMDA autoreceptors in olfactory mitral cells. J Neurophysiol 84:39-50.

Halpern BP (1983) Tasting and smelling as active, exploratory sensory processes. Am J Otolaryngol 4:246-249.

Heyward PM, Shipley MT (1999) Non-inactivating TTX-sensitive inward current contributes to the depolarized up-state in bistable mitral cells of the main olfactory bulb. Soc Neurosci Abstr 25:691.17.

Heyward PM, Shipley MT (2000a) A persistent sodium current generates up-state plateau potentials and active subthreshold responses to olfactory nerve $(\mathrm{ON})$ input in mitral cells of the main olfactory bulb. Ass Chemoreception Sci Abstr 22:162.

Heyward PM, Shipley MT (2000b) Mitral cell intrinsic membrane properties amplify responses to olfactory nerve synaptic input. Soc Neurosci Abstr 26:609.15.

Heyward PM, Chen C, Clarke IJ (1995) Inward membrane currents and electrophysiological responses to GnRH in ovine gonadotrophs. Neuroendocrinology 61:609-621.

Heyward PM, Tian Y, Shipley MT (1999) Electrophysiology of identified mitral and tufted cells in the main olfactory bulb (MOB). Ass Chemoreception Sci Abstr 21:148.

Hodgkin AL, Huxley AF (1952) A quantitative description of membrane current and its application to conduction and excitation in nerve. Bull Math Biol 52:25-71.

Isaacson JS (1999) Glutamate spillover mediates excitatory transmission in the rat olfactory bulb. Neuron 23:377-384.

Isaacson JS, Strowbridge BW (1998) Olfactory reciprocal synapses: dendritic signaling in the CNS. Neuron 20:749-761.

Jahnsen H, Llinas R (1984a) Electrophysiological properties of guineapig thalamic neurons; an in vitro study. J Physiol (Lond) 349:205-226.

Jahnsen H, Llinas R (1984b) Ionic basis for the electroresponsiveness and oscillatory properties of guinea-pig thalamic neurons in vitro. J Physiol (Lond) 349:227-247.

Jiang M, Griff ER, Enis M, Zimmer LA, Shipley MT (1996) Activation of locus coeruleus enhances the response of olfactory bulb mitral cells to weak olfactory nerve input. J Neurosci 16:6319-6329.

Johnston D, Magee JC, Colbert CM, Cristie BR (1996) Active properties of neuronal dendrites. Annu Rev Neurosci 19:165-186.

Kay AR, Sugimori M, Llinas R (1998) Kinetic and stochastic properties of a persistent sodium current in mature guinea-pig cerebellar Purkinje cells. J Neurophysiol 80:1167-1179.

Kiehn O (1991) Plateau potentials and active integration in the "final common pathway" for motor behavior. Trends Neurosci 14:68-73.

Lenz RA, Pitler TA, Alger BE (1997) High intracellular Cl- concentrations depress G-protein-modulated ionic conductances. J Neurosci 17:6133-6141.

Llinas RR (1988) The intrinsic electrophysiological properties of mammalian neurons: insights into central nervous system function. Science 242:1654-1664.

Llinas R, Sugimori M (1980a) Electrophysiological properties of in vitro Purkinje cell somata in mammalian cerebellar slices. J Physiol (Lond) 305:171-195.

Llinas R, Sugimori M (1980b) Electrophysiological properties of in vitro Purkinje cell dendrites in mammalian cerebellar slices. J Physiol (Lond) 305:197-213.

Marder E, Abbott LF, Turrigiano GG, Liu Z, Golowasch G (1996) Memory from dynamics of intrinsic membrane currents. Proc Natl Acad Sci USA 93:13481-13486.

Mercer AR, Kloppenburg P, Hildebrand JG (2000) Plateau potentials in antennal lobe neurons of the sphinx moth, Manduca sexta. Soc Neurosci Abstr 26:28.14.

Mitmann T, Linton SM, Schwindt P, Crill W (1997) Evidence for persistent $\mathrm{Na}^{+}$current in apical dendrites of rat neocortical neurons from imaging of $\mathrm{Na}^{+}$-sensitive dye. J Neurophysiol 78:1188-1192.
Mombaerts P, Wang F, Dulac C, Chao SK, Nemes A, Mendelshon M, Edmondson J, Axel R (1996) Visualizing an olfactory sensory map. Cell 87:675-686.

Ochs S, Pourmand R, Jersild Jr RA, Friedman RN (1997) The origin and nature of beading: a reversible transformation of the shape of nerve fibers. Prog Neurobiol 52:391-426.

Ramon y Cajal S (1894) Les nouvelles idées sur la structure du système nerveux chez l'homme et chez les vertebras (Azoulay L, translator). Paris: C. Reinwald et Cie.

Russell DF, Hartline DK (1982) Slow active potentials and bursting motor patterns in pyloric network of the lobster, Panulirus interruptus. J Neurophysiol 48:914-937.

Sandler VM, Puil E, Schwarz DW (1998) Intrinsic response properties of bursting neurons in the nucleus principalis trigemini of the gerbil. Neuroscience 83:891-904.

Scholfield H (1981) Intracellular and extracellular recordings in the isolated olfactory cortex slice and some problems associated with assessing drug action. In: Electrophysiology of isolated mammalian CNS preparations (Kerkut GA, Wheal HV, eds), pp 133-152. London: Academic.

Schoppa NE, Westbrook GL (1999) Regulation of synaptic timing in the olfactory bulb by an A-type potassium current. Nat Neurosci 2:1106-1113

Schoppa NE, Kinzie JM, Sahara Y, Segerson TP, Westbrook GL (1998) Dendrodendritic inhibition in the olfactory bulb is driven by NMDA receptors. J Neurosci 18:6790-6802.

Schwartzkroin PA (1981) To slice or not to slice. In: Electrophysiology of isolated mammalian CNS preparations (Kerkut GA, Wheal HV, eds), pp 15-50. London: Academic.

Schwindt P, Crill W (1999) Mechanisms underlying burst and regular spiking evoked by dendritic depolarization in layer 5 cortical pyramidal neurons. J Neurophysiol 81:1341-1354.

Shipley MT, Ennis M (1996) Functional organization of olfactory system. J Neurobiol 30:123-176.

Shipley MT, McLean JH, Zimmer LA, Ennis M (1996) The olfactory system. In: Handbook of chemical neuroanatomy. Integrated systems of the CNS, 12(III) (Bjorklund A, Hokfelt T, Swanson LW, eds), pp 467-571. Amsterdam: Elsevier.

Stuart GJ, Dodt HU, Sakmann B (1993) Patch-clamp recordings from the soma and dendrites of neurons in brain slices using infrared video microscopy. Pflügers Arch 423:511-518.

Teyler TJ (1980) Brain slice preparation: hippocampus. Brain Res Bull 5:391-403.

Trombley PQ, Hill BJ, Horning MS (1999) Interactions between GABA and glycine at inhibitory amino acid receptors on rat olfactory bulb neurons. J Neurophysiol 82:3417-3422.

Waranch HR, Terman M (1975) Control of the rat's sniffing behavior by response-independent and dependent schedules of reinforcing brain stimulation. Physiol Behav 15:365-372.

Williams SR, Toth TI, Turner JP, Hughes SW, Crunelli C (1997) The "window" component of the low threshold $\mathrm{Ca}^{2+}$ current produces signal amplification and bistability in cat and rat thalamocortical neurones. J Physiol (Lond) 505:689-704.

Wilson CJ, Kawaguchi Y (1996) The origins of two-state spontaneous membrane potential fluctuations of neostriatal spiny neurons. J Neurosci 16:2397-2410.

Yokoi M, Mori K, Nakanishi S (1995) Refinement of odor molecule tuning by dendrodendritic synaptic inhibition in the olfactory bulb. Proc Natl Acad Sci USA 92:3371-3375.

Yuen GL, Hockenberger PE, Houk JC (1995) Bistability in Purkinje cell dendrites modeled with high-threshold calcium and delayed-rectifier potassium channels. Biol Cybern 73:375-388. 